\title{
Muscle activity during stance phase of walking: Comparison of males with transfemoral amputation with osseointegrated fixations to nondisabled male volunteers
}

\author{
Annette Pantall, DO(UK), PhD; ${ }^{1-2 *}$ David Ewins, PhD $^{2-3}$ \\ ${ }^{1}$ Georgia Institute of Technology, Atlanta, GA; ${ }^{2}$ Centre for Biomedical Engineering, University of Surrey, Guildford, \\ United Kingdom; ${ }^{3}$ Douglas Bader Rehabilitation Centre, Queen Mary’s Hospital, London, United Kingdom
}

\begin{abstract}
A recent development in prosthetics is the osseointegrated fixation (OF), with improvements in comfort, fatigue, hip movement, and ease of prosthetic attachment reported. However, little information is available regarding muscle function. This study reports on selected gait parameters of the residual limb during the stance phase of level overground walking, focusing on muscle activity. Five males with transfemoral amputation (TFA) with OFs were recruited. Ground reaction force (GRF), lower-limb kinematics, and surface electromyography (sEMG) from residual-limb muscles were recorded. sEMG data were also collected from a group of 10 nondisabled male subjects. Interstance variability of gait parameters was assessed by coefficient of multiple correlations. Repeatability of GRF and hip kinematics was high, whereas repeatability of the SEMG was low for four of the five individuals with TFA. Interstance variability of the sEMG for gluteus medius (GMED) was significantly greater in the group with TFA. The main difference in sEMG between the groups was the phase, with GMED and adductor magnus displaying greater differences than their counterparts in the nondisabled group. Results demonstrate that muscles in the residual limb retain aspects of their previous functional pattern.
\end{abstract}

Key words: amputation, direct skeletal fixation, electromyography, EMG, gait, locomotion, osseointegrated fixation, residual limb, transected muscle, transfemoral amputation.

\section{INTRODUCTION}

Development of prosthetic limbs for individuals with transfemoral amputation (TFA) has advanced considerably, with the introduction of new materials, improved socket design, and increasing sophistication of prosthetic joints including feedback control systems [1]. However, despite current developments, approximately one-quarter of individuals with TFA remain dissatisfied with their prosthesis [2]. Socket discomfort, difficulty of attachment, control of the prosthetic limb, and increased energy expenditure during daily functional activities are factors contributing to the dissatisfaction. One of the main challenges in improving functional outcome lies in achieving a successful interface between the extrinsic components (prosthesis and attachment) and the intrinsic component (residual

\footnotetext{
Abbreviations: $\mathrm{AM}=$ adductor magnus, $\mathrm{BF}=$ biceps femoris, $\mathrm{BMI}=$ body mass index, $\mathrm{CMC}=$ coefficient of multiple correlation, GMAX = gluteus maximus, GMED = gluteus medius, GRF $=$ ground reaction force, $\mathrm{MAV}=$ moving average value, $\mathrm{OF}=$ osseointegrated fixation, OPRA $=$ Osseointegrated Prosthesis for Rehabilitation of Amputees, $\mathrm{RF}=$ rectus femoris, $\mathrm{sEMG}=$ surface electromyography, TFA = transfemoral amputation.

*Address all correspondence to Annette Pantall, DO(UK), PhD; Michigan State University, College of Osteopathic Medicine, Department of Osteopathic Manipulative Medicine, East Fee Hall, 965 Fee Road, East Lansing, MI 488241316. Email: pantall@msu.edu http://dx.doi.org/10.1682/JRRD.2011.10.0204
} 
limb) at both the mechanical and control levels. A recent innovation that establishes a structural interface is the osseointegrated fixation (OF). Although this was originally conceived in the 1880s as described in Murphy's comprehensive account of early attachment of prostheses to the skeleton [3], the first successful implant was not realized until 1990 [4]. In Europe, three types of systems are currently under development: the Intraosseous Transcutaneous Amputation Prosthesis [5-6], the Endo-Exo Femur Prosthesis [7-8] and the Osseointegrated Prosthesis for Rehabilitation of Amputees (OPRA) [4,9-10]. The OPRA has the longest history, with several published patient outcomes, and is the system that the individuals in this study had implanted [4,9-12]. This procedure is still experimental, with fewer than 150 reported cases globally $[7,9]$. Decreased energy expenditure, increased functional outcome, increased range of hip movement, improved seating comfort, and ease of attachment of the prosthetic limb in subjects fitted with an OF are some of the benefits that have been reported [9-13].

Future progress lies in further synthesis of the prosthesis with the residual limb, both biomechanically and through a computer-controlled system. A direct biomechanical interface is achieved through connections from muscles or tendons to an extrinsic prosthetic component, a concept presented nearly a century ago by Biesalski and more recently by Weir et al. [14-15]. The OF increases the feasibility of a continuous interface between musculotendinous tissue and the prosthesis through its internal interaction with human tissue. Microprocessor-controlled systems involve transmitting signals from sensors intrinsic to the prosthesis (e.g., accelerometers, load cells, and gyrometers) or physiological sensors (signals emanating from muscles and nerves) to a microcomputer that modifies movement of the prosthetic device $[1,16]$. The advantage of incorporating sensors detecting signals from nerves or muscles is that they may convey information regarding the subject's movement control strategy. Electrodes measuring surface electromyography (sEMG) represent the least invasive type of natural sensor for motor control. sEMG sensors, or myoprocessors, have been successfully incorporated in the upper limb, although not as yet in the lower limb during locomotion [17-20]. One reason why sEMG has not been successfully employed in lower-limb prostheses during locomotion is that the muscle contraction is fluctuating in intensity and duration, producing a nonstationary stochastic signal [21].
Greater incorporation of the residual limb with the prosthetic component requires understanding of morphology, physiology, and biomechanics of the restructured limb, in particular the altered function of muscles. A TFA produces structural remodeling and altered functional role of the muscles of the residual limb. For example, rectus femoris (RF) and biceps femoris (BF) are transformed into uniarticular muscles, no longer having an action on the knee joint. These two muscles together with adductor magnus (AM) lose their fixed insertion points and therefore lack a strong anchor point on which to exert a force. RF therefore is no longer attached to the base of the patella, BF loses its connection to the fibula and tibia, and the hamstring portion of AM's insertion to the adductor tubercle of the femur is lost. Instead, the transected muscles are sutured to the distal periosteum and myofascia [22]. The precise surgical attachment of transected muscles will depend on various factors, including the length of the residual limb and the individual's anatomy. The potential force the transected muscle is able to apply to the femur will therefore vary between individuals. Subjects with high-level TFA lose much of the short head of the BF, thus changing the muscle from bicipital to unicipital. The properties of gluteus maximus's (GMAX's) attachment point to the iliotibial tract are modified because the tract is cleaved, thereby creating a mobile anchorage site. This muscle also has to functionally adapt to the imbalance that develops in the residual limb, with iliopsoas pulling the hip joint into flexion against the weakened hamstring group of muscles. Although gluteus medius (GMED) is anatomically unaltered in individuals with TFA, functionally it will be affected as a result of the decrease in force of the adductor group. Although the effect of gross measures, such as the length of the residual limb or method of muscle fixation on clinical outcome have been reported, there is a dearth of research on changes that develop in the anatomy, histology, and function of muscles in the residual limb following amputation [23-26]. Jaegers et al. (1995) have reported 10-73 percent atrophy in the muscles of the residual limb of individuals with TFA, the atrophy being greater in cleaved muscles, biarticular muscles, and weakly anchored muscles [24]. Few sEMG studies have been performed on individuals with TFA during walking, the main one being by Jaegers et al. (1996) [27]. The only published report of sEMG in individuals with TFA fitted with an $\mathrm{OF}$ indicated changes in frequency of AM during isometric contraction [28]. In addition to the amplitude of 
the sEMG, intrasubject variability is an important gait determinant because it indicates stability of the control system, an essential factor in the development of further synthesis between the residual limb and prosthesis. Only the intrasubject variability of loading parameters during walking in individuals with OF has previously been reported [29].

The purpose of the study was to examine the patterns and variability in sEMG activity of hip joint muscles, vertical ground reaction force (GRF), and hip joint angles during the stance phase of walking in individuals with TFA with OFs. Locomotion has been selected because it is the most important functional activity for individuals with TFA [30]. Only the stance phase was analyzed because it is functionally more demanding than the swing phase of the gait cycle, with highest peaks in hip power, and it is during this phase that control by a myoprocessor is most critical [31]. A further factor for selecting the stance phase is that the highest error in identification of locomotion mode based on sEMG from gluteal and residual thigh muscles was reported during this phase in individuals with TFA [32]. Because the cleaved muscles, specifically RF, AM, and BF, no longer have a fixed bony distal insertion point, their functional role as actuators of the hip joint are diminished. Additionally the ability of the transected muscles to transmit force will vary as a consequence of differences in surgical attachments. An anticipated outcome of this loss of function is a lessdefined cyclical pattern of muscle activity as well as greater variability in muscle activity between stances. The first hypothesis investigated was that the cyclical pattern exhibited in intact muscles would be absent in individuals with OFs. The second hypothesis was that interstance variability of muscle activity would be greater in individuals with OFs than in nondisabled individuals.

\section{METHODS}

\section{Procedure}

Study group A consisted of 5 male individuals with TFA fitted with OFs and study group B of 10 male control subjects with intact limbs, all volunteers. The criteria for individuals with TFA were in accordance with those described by Sullivan et al. (2003) [12]. The criteria for group B subjects were that they must (1) be in good medical health; (2) not have any pathology, significant congenital abnormality, trauma, or history of surgery that has affected their gait pattern; (3) not be clinically obese (body mass index [BMI] $>30 \mathrm{~kg} / \mathrm{m}$ ); and (4) be male between 10 and $65 \mathrm{yr}$ of age. All individuals with TFA had their limb removed more than 8 yr ago, were fitted more than 2 yr previously with OF (titanium implant with mechanical fixing and titanium abutment; Integrum AB; Mölndal, Sweden), and were able to walk unaided. The implant and abutment were in line with the long axis of the femur. The exoprosthesis was set up such that in the coronal (frontal) plane, the long axis of the exoprosthesis was in line with the abutment; in the sagittal plane, the long axis of the exoprosthesis was vertical at midstance; and in the transverse plane, the foot was parallel to the nominal direction of progression at midstance (i.e., neither in- or out-toed). Table 1 provides selected characteristics of the individuals with TFA. The sEMG was measured from five hip muscles of the residual limb and from the right lower limb in the control subjects. The muscles recorded were GMAX, GMED, RF, AM, and $\mathrm{BF}$. These muscles were selected because they are all superficial and exert different moments about the hip joint. The signal was collected using the Biometrics DataLINK DLK800 system (Biometrics Ltd; Gwent, United Kingdom) with surface preamplifier type SX230 at a sampling rate of $1,000 \mathrm{~Hz}$. The site selected for GMAX and GMED was in the location recommended by SENIAM (Surface ElectroMyoGraphy for the Non-Invasive Assessment of Muscles) [33]. The electrode placement for RF, AM, and BF was determined by palpation and resistive testing. Figure 1 illustrates placement of the electrodes.

In addition to the sEMG electrodes, group A also had retroreflective markers placed on their lower limbs and pelvis in locations specified by a modified Helen Hayes system (Figure 2).

Kinematic data were recorded only in the individuals with TFA using a six-camera $60 \mathrm{~Hz}$ MacReflex marker detection system (Qualisys Medical AB; Partille, Sweden). GRFs were collected using a 3.3 m dual-platform walkway developed at the Gait Laboratory (Queen Mary's Hospital; London, United Kingdom) [34] at a sampling rate of 2,000 Hz. Each subject was asked to perform three isometric contractions for $10 \mathrm{~s}$ for each of five muscles against resistance. The purpose of this was to aid in correct location of the electrodes [28]. Recordings took place while the subjects were lying supine for $\mathrm{RF}, \mathrm{AM}$, and $\mathrm{BF}$ and then either on their intact lowerlimb side for the group A or on their left side for group B 
JRRD, Volume 50, Number 4, 2013

Table 1.

Description of 5 subjects with transfemoral amputation fitted with osseointegrated fixation (OF).

\begin{tabular}{|c|c|c|c|c|c|c|c|}
\hline Subject & $\begin{array}{c}\text { Amputation } \\
\text { Reason }\end{array}$ & $\begin{array}{l}\text { Amputation } \\
\text { Side }\end{array}$ & $\begin{array}{l}\text { Dominant } \\
\text { Side }\end{array}$ & $\begin{array}{c}\text { Time of } \\
\text { Amputation } \\
\text { Before Study (yr) }\end{array}$ & $\begin{array}{c}\text { Time of OF Surgery } \\
1^{*} \text { and } 2^{\dagger} \text { Before } \\
\text { Study }(\mathrm{yr})\end{array}$ & $\begin{array}{l}\text { Residual-Limb } \\
\text { Length from } \\
\text { Perineum (mm) }\end{array}$ & $\begin{array}{l}\text { Exoprosthesis } \\
\text { at Study }\end{array}$ \\
\hline A1 & RTA & Right & Right & 14.3 & $\begin{array}{l}\text { OF surgery 1: 4.6; } \\
\text { OF surgery 2: } 4.1\end{array}$ & 185 & $\begin{array}{l}\text { OB 3R80, OB 1D10 foot, } \\
\text { OB 4R39 torsion adaptor }\end{array}$ \\
\hline A2 & RTA & Left & Right & 15.4 & $\begin{array}{l}\text { OF surgery 1: 5.6; } \\
\text { OF surgery 2: } 5.1\end{array}$ & 245 & $\begin{array}{l}\text { OB 3R80, OB 1D10 foot, } \\
\text { OB 4R39 torsion adaptor }\end{array}$ \\
\hline A3 & RTA & Right & Right & 14.0 & $\begin{array}{l}\text { OF surgery } 1: 6.8 \text {; } \\
\text { OF surgery 2: } 6.2\end{array}$ & 191 & $\begin{array}{l}\text { OB C-Leg, OB 1D10 } \\
\text { foot, OB 4R39 torsion } \\
\text { adaptor }\end{array}$ \\
\hline A4 & RTA & Right & Right & 17.3 & $\begin{array}{l}\text { OF surgery } 1: 2.7 ; \\
\text { OF surgery } 2: 2.2\end{array}$ & 225 & $\begin{array}{l}\text { OB 3R80, OB 1D10 foot, } \\
\text { OB 4R39 torsion adaptor }\end{array}$ \\
\hline A5 & Gunshot & Left & Right & 8.3 & $\begin{array}{l}\text { OF surgery 1: 4.6; } \\
\text { OF surgery 2; } 4.1\end{array}$ & 235 & $\begin{array}{l}\text { OB 3R80 knee, OB 1D10 } \\
\text { foot, OB 4R39 torsion } \\
\text { adaptor }\end{array}$ \\
\hline
\end{tabular}

for GMAX and GMED. We collected $30 \mathrm{~s}$ of data from the relaxed muscles. The subjects were then asked to resist extension, flexion, adduction, and abduction of the hip joint for approximately $10 \mathrm{~s}$. The force applied to the prosthetic limb in group A or the right lower limb in group B was either the maximum force that the subject was comfortable with or the maximum that the experimenter could apply. The sEMG trace was checked in real time and adjustments were made to the amplification for both groups and position of the electrodes where necessary for the group with TFA.

Following this, the subjects practiced walking along the walkway to become accustomed to walking with

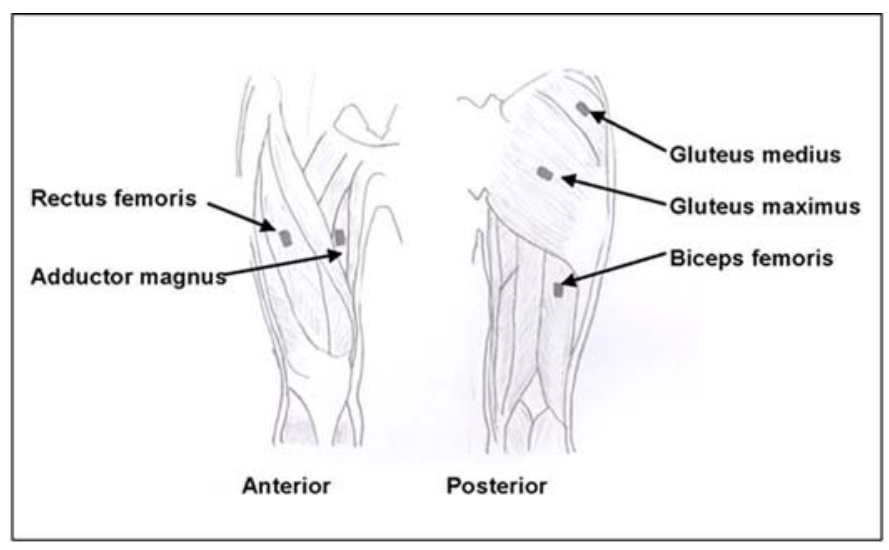

Figure 1.

Schematic diagram illustrating placement of electrodes on right lower limb. attached electrodes and markers. They were then requested to walk at their normal pace along a $10 \mathrm{~m}$ walkway containing the dual $3.3 \mathrm{~m}$ force plates in the center until approximately 20 complete contacts on a single plate had been recorded. The number of recorded trials ranged from 10 to 23 .

\section{Data Reduction}

The average walking speed for both groups was computed from the force plate data by customized software developed at the Gait Laboratory [34]. Normalization of the gait speed relative to leg length was calculated according to Hof [35]. Hip and knee joint kinematic data were processed using Visual3D version 3.13.0 software (CMotion Inc; Germantown, Maryland) for the individuals with TFA. The sEMG, GRF, and kinematic data were processed by a customized MATLAB 6.5 program (The MathWorks; Natick, Massachusetts). Gait cycles and stance/swing phases were identified by using timings determined from applying a threshold $(5 \mathrm{~N})$ to the vertical GRF recorded by the force plates. The hip angle was defined as the angle between the thigh segment and Helen Hayes pelvis segment (coordinate segment and reference). Flexion, adduction, and rotation were calculated as the transformation about the relevant axis using the appropriate Cardan sequence. The knee angle was defined as the angle between the shank segment and the reference thigh segment with the appropriate transformation about the mediolateral axis to determine flexion/extension. 


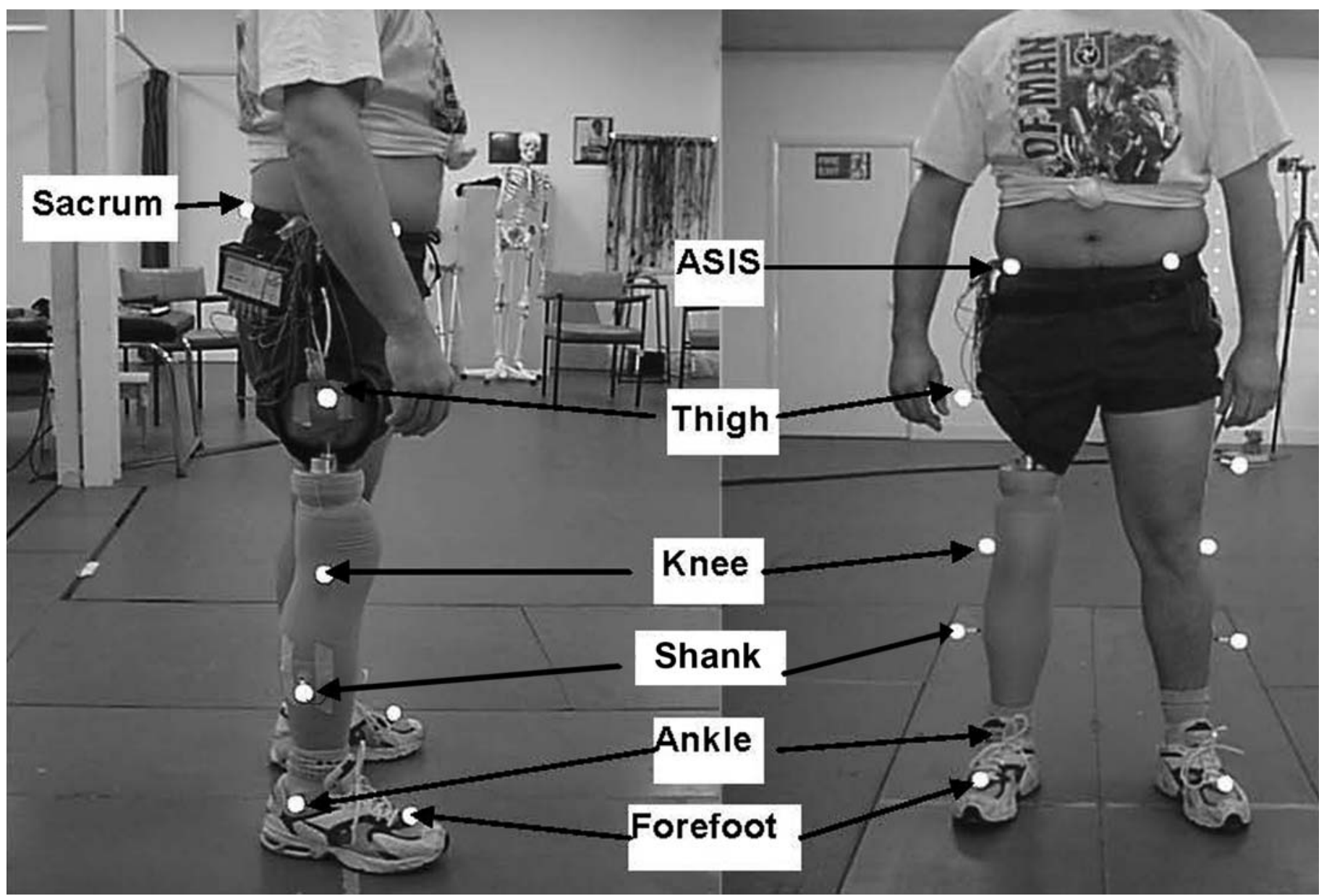

Figure 2.

Subject with transfemoral amputation with lower-limb markers attached according to modified Helen Hayes marker system. ASIS = anterior superior iliac spine.

The moving average value (MAV) of sEMG was calculated using zero phase digital filtering with a window of $100 \mathrm{~ms}$. Each variable was time normalized to 30 points by using cubic spline interpolation. The duration between time points was sufficiently long, approximately $20 \mathrm{~ms}$, to detect physiological changes in muscle activity. The sEMG MAVs were normalized to the maximum amplitude recorded during the trial for each subject and muscle and divided into individual stance and swing cycles [36]. Pearson correlation coefficient (r), coefficient of variation, variance ratio, coefficient of multiple correlation (CMC), and intraclass correlation coefficient are methods that have been commonly used to determine variability. The advantage of the CMC is that it considers the changes in the overall waveform [37]. The interstance variability was determined by calculating the CMC according to the following algorithm [36]:

$$
C M C=1-\sum_{j=1}^{N} \sum_{t=1}^{T} \frac{\left(x_{j t}-\bar{x}_{t}\right)^{2} / T(N-1)}{\left(x_{j t}-\bar{x}\right)^{2} / N T-1},
$$

where $N$ is the number of stances, $T$ is the number of time points, $x_{j t}$ is the value at the th time point of the $j$ th stance.

CMC values range between 0 and 1 , with values above 0.8 suggesting a high degree of reproducibility and values approaching zero indicating low reproducibility [38-39]. CMC values were also calculated for the hip joint angular data and for the GRF data for the individuals with TFA. 


\section{Statistical Analysis}

Statistical analysis was performed using the Statistics Toolbox of MATLAB 6.5. Given the small size of the group with TFA, $n=5$, the data were considered nonparametric because normality tests do not provide an indication of nonnormality because of a lack of power. The MannWhitney $U$ test was used to test for significant differences in the demographic characteristics, temporal gait parameters, and sEMG CMC values between the two groups. The level of statistical significance was set at 0.05 .

\section{RESULTS}

The characteristics of the groups differed significantly regarding age, mass, and BMI (Table 2).

\section{Gait Temporospatial Parameters}

The median gait cycle was significantly longer for group A (1.16 vs $1.07 \mathrm{~s}$ ) and the median percentage of gait cycle accounted for by the stance phase was signi- ficantly lower for group A (57.1\% vs 62.4\%) (Table 2). Although both mean speed and normalized speed were lower for group A than group B, the difference was not significant. Similarly, the cadence, although lower for group A, was not significantly different from group B.

\section{Ground Reaction Force and Hip and Knee Joint Kinematics of Group with Osseointegrated Fixation}

The vertical GRF profiles for the five individuals with OF all exhibited a double-peaked profile, as shown in the exemplar GRF trace (Figure 3(d)). The CMC values ranged from 0.99 to 1.00 (Table 3).

Fewer stances were available for analysis of kinematic data, because in some instances the markers were not detected. Group A individuals displayed a similar pattern of sagittal angular displacement of the hip joint with the hip extending at heel strike, continuing through until toe-off when flexion commenced. Subjects A2 and A3 extended their hips until just before toe-off, whereas subjects A1, A4, and A5 were still extending their hip joints at toe-off. The median maximum hip extension was $16.2^{\circ}$ (range $8.4^{\circ}$ to $18.7^{\circ}$ ). In the coronal plane, the

Table 2.

Subject and temporospatial parameters for group A (subjects A1-A5 with transfemoral amputation and osseointegrated fixation, $n=5$ ) and group B (subjects B1-B10 with intact limbs, $n=10$ ).

\begin{tabular}{|c|c|c|c|c|c|c|c|c|c|c|}
\hline Subject & $\begin{array}{l}\text { Age } \\
\text { (yr) }\end{array}$ & $\begin{array}{c}\text { BMI } \\
\left(\mathrm{kg} / \mathrm{m}^{2}\right)\end{array}$ & $\begin{array}{c}\text { Height } \\
\text { (m) }\end{array}$ & $\begin{array}{c}\text { Mass } \\
(\mathbf{k g})\end{array}$ & $\begin{array}{c}\text { No. } \\
\text { Stances }\end{array}$ & $\begin{array}{c}\text { Speed } \\
(\mathrm{m} / \mathrm{s})\end{array}$ & $\begin{array}{l}\text { Normalized } \\
\text { Speed }\end{array}$ & $\begin{array}{c}\text { Gait Cycle } \\
\text { Duration (s), } \\
\text { Mean } \pm \text { SD }\end{array}$ & $\begin{array}{c}\text { Cadence } \\
\text { (steps/min) }\end{array}$ & $\begin{array}{c}\text { Stance Phase } \\
\text { (\% gait cycle), } \\
\text { Mean } \pm \text { SD }\end{array}$ \\
\hline \multicolumn{11}{|l|}{ Group A } \\
\hline A2 & 45 & 27.5 & 1.83 & 92.0 & 23 & 1.20 & 0.41 & $1.16 \pm 0.02$ & 124.1 & $53.4 \pm 1.1$ \\
\hline A3 & 31 & 31.3 & 1.77 & 98.2 & 21 & 1.21 & 0.42 & $1.18 \pm 0.04$ & 123.1 & $57.0 \pm 0.7$ \\
\hline A4 & 41 & 28.9 & 1.71 & 84.4 & 27 & 1.25 & 0.44 & $1.08 \pm 0.03$ & 138.9 & $60.2 \pm 0.4$ \\
\hline Range & $31-45$ & 26.7-31.3 & $1.68-1.83$ & 75.3-98.2 & $18-23$ & $1.06-1.34$ & $0.38-0.47$ & $1.08-1.18$ & 107.8-143.6 & 53.4-63.6 \\
\hline \multicolumn{11}{|l|}{ Group B } \\
\hline B1 & 33 & 22.0 & 1.90 & 79.3 & 25 & 1.12 & 0.37 & $1.01 \pm 0.03$ & 112.7 & $66.2 \pm 1.4$ \\
\hline B2 & 41 & 24.1 & 1.75 & 73.8 & 34 & 1.51 & 0.40 & $1.00 \pm 0.01$ & 138.3 & $60.5 \pm 0.4$ \\
\hline B3 & 25 & 24.7 & 1.71 & 72.10 & 28 & 1.54 & 0.53 & $1.00 \pm 0.02$ & 180.8 & $61.3 \pm 0.9$ \\
\hline B8 & 32 & 20.1 & 1.88 & 70.9 & 34 & 1.55 & 0.52 & $1.08 \pm 0.07$ & 172.4 & $63.2 \pm 1.0$ \\
\hline B9 & 27 & 24.1 & 1.78 & 76.4 & 27 & 1.24 & 0.43 & $1.12 \pm 0.02$ & 132.8 & $62.6 \pm 0.8$ \\
\hline B10 & 25 & 16.8 & 1.91 & 61.4 & 17 & 1.65 & 0.55 & $1.07 \pm 0.04$ & 184.7 & $61.8 \pm 1.7$ \\
\hline Median & $26^{*}$ & $24.1^{*}$ & 1.77 & $75.1^{*}$ & 26 & 1.43 & 0.47 & $1.07^{*}$ & 146.9 & $62.4^{*}$ \\
\hline Range & $16-41$ & $16.8-27.4$ & $1.71-1.91$ & 61.4-83.9 & $17-34$ & $1.12-1.74$ & $0.37-0.61$ & $1.00-1.16$ & 112.7-194.4 & $60.5-66.2$ \\
\hline
\end{tabular}



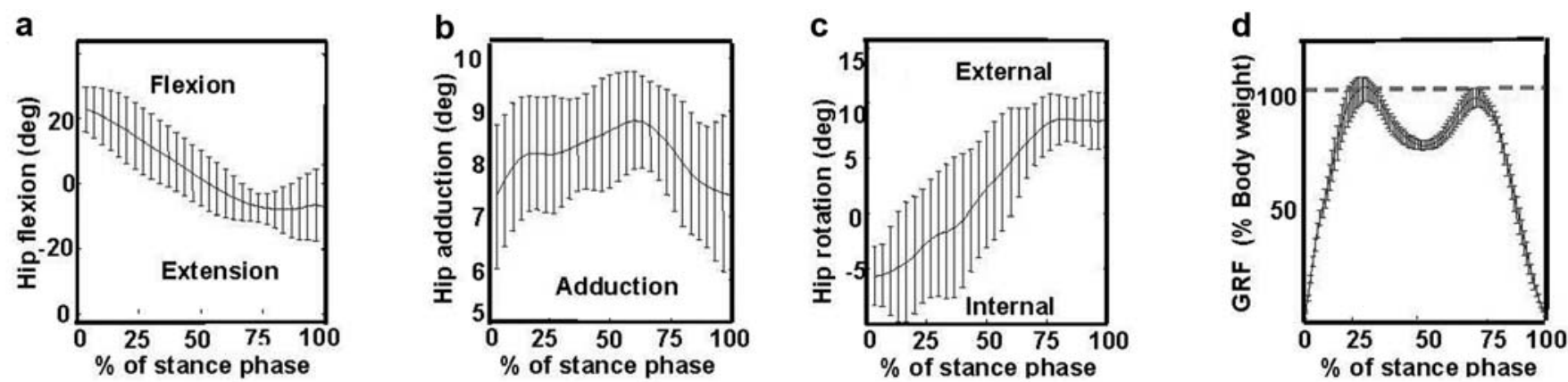

Figure 3.

Kinetic and kinematic parameters of residual limb of subject A4 during stance phase of gait cycle, with standard deviation bars marked. (a) Hip joint flexion/extension, $n=23$ stances. (b) Hip joint adduction/abduction, $n=23$ stances. (c) Hip joint external/internal rotation, $n=23$ stances. (d) Vertical ground reaction force, $n=27$ stances.

Table 3.

Coefficient of multiple correlation for interstance kinetic and kinematic parameters of subjects with transfemoral amputation.

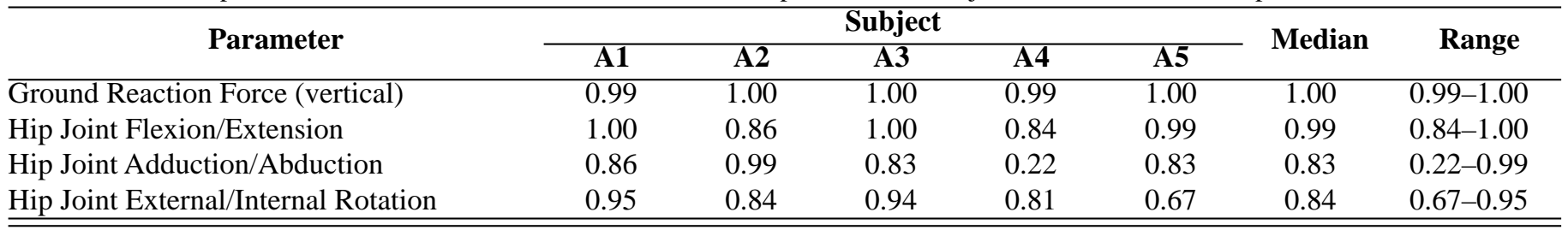

median maximum abduction was $13.2^{\circ}$ (range $8.8^{\circ}$ to $14.3^{\circ}$ ) during the stance phase for group A individuals (Table 4). The kinematic pattern in the transverse plane was more variable during stance, with subjects displaying patterns of both internal and external rotation. Figure 3(a)-3(c) illustrates kinematic patterns for subject A4 with TFA. The CMC calculated for the hip joint angular displacement was high for the group, with values above 0.80 , with the exceptions of the hip joint adduction/ abduction angle for subject A4 and the hip joint rotation angle for subject A5 (Table 3).

Table 5 presents timing of specific gait events for GRF, hip flexion, and knee flexion for individuals with TFA. Additionally, the magnitude of GRF at the bimodal peaks is recorded. All five individuals with TFA reached close to or above body weight at the first peak, with timing of maximal loading varying from 15.3 percent of the stance phase for subject A1 to 27.0 percent for subject A5. Subject A2 displayed the earliest second peak at 63.2 percent compared with subject A3, who recorded the latest second peak at 71.9 percent of stance phase. The kinematic timings show subject A 1 commenced hip flexion latest in the stance cycle (97.4\%) compared with the earliest (89.9\%) displayed by subject A4. The subject who varied the most in knee flexion was subject A3, whose onset of knee flexion at 88.9 percent of the stance cycle occurred more than 20 percent later than the remaining individuals with TFAs.

\section{Surface Electromyography}

All the ensemble sEMG recordings for both groups displayed cyclical patterns, with the exception of the signal for GMAX for subject A2, where a clear signal was not obtained. Figure 4 shows an exemplar trace for bandpass-filtered unnormalized sEMG for subject A1 for a single trial. Cyclical patterns can be discerned, with GMAX and GMED displaying more activity for the two swing phases (shaded green) and AM and BF showing more activity during the three stance phases (shaded yellow). The mean ensemble MAV trace for all muscles in group A displayed similar gross patterns, maximal at the beginning of stance, decreasing to a minimum midcycle, and then attaining a smaller peak during the second half of the phase (Figure 5).

In group A, hip extensors and flexors attained a minimum in sEMG activity later, at about 50 percent of the stance phase, than the adductor AM and abductor GMED, which had minimal activity at about 43 percent 
Table 4.

Minimum and maximum joint angles (mean \pm standard deviation) during stance phase of walking in sagittal (flexion $=$ positive, extension $=$ negative), coronal (abduction = positive, adduction = negative), and transverse planes (external rotation = positive, internal rotation = negative) .

\begin{tabular}{|c|c|c|c|c|c|c|c|}
\hline \multirow[b]{2}{*}{ Subject } & \multirow{2}{*}{$\begin{array}{c}\text { No. } \\
\text { Stances }\end{array}$} & \multicolumn{2}{|c|}{ Sagittal Plane } & \multicolumn{2}{|c|}{ Coronal Plane } & \multicolumn{2}{|c|}{ Transverse Plane } \\
\hline & & $\begin{array}{l}\text { Minimum } \\
\left.\text { Angle ( }{ }^{\circ}\right)\end{array}$ & $\begin{array}{c}\text { Maximum } \\
\left.\text { Angle ( }{ }^{\circ}\right)\end{array}$ & $\begin{array}{l}\text { Minimum } \\
\left.\text { Angle ( }{ }^{\circ}\right)\end{array}$ & $\begin{array}{c}\text { Maximum } \\
\text { Angle }\left(^{\circ}\right)\end{array}$ & $\begin{array}{c}\text { Minimum } \\
\left.\text { Angle ( }{ }^{\circ}\right)\end{array}$ & $\begin{array}{c}\text { Maximum } \\
\text { Angle }\left(^{\circ}\right)\end{array}$ \\
\hline$\overline{\mathrm{A} 1}$ & 18 & $-16.0 \pm 0.6$ & $31.7 \pm 0.9$ & $4.0 \pm 2.6$ & $10.2 \pm 0.7$ & $-29.0 \pm 1.2$ & $-6.6 \pm 1.0$ \\
\hline A3 & 7 & $-18.7 \pm 1.4$ & $29.2 \pm 1.2$ & $5.1 \pm 8.2$ & $13.2 \pm 1.6$ & $-2.1 \pm 0.8$ & $14.2 \pm 1.6$ \\
\hline A4 & 23 & $-8.4 \pm 6.9$ & $22.6 \pm 7.0$ & $7.4 \pm 1.4$ & $8.8 \pm 2.3$ & $-5.7 \pm 2.7$ & $8.5 \pm 2.3$ \\
\hline Range & $7-23$ & $-18.7-(-8.4)$ & $22.6-31.7$ & $4.0-8.4$ & 8.8-14.3 & $-2.1-29.0$ & $-6.6-26.8$ \\
\hline
\end{tabular}

Table 5.

Timing and amplitude of first and second peak of mean vertical ground reaction force and onset of hip and knee flexion of residual limb for subjects A1-A5 with transfemoral amputation.

\begin{tabular}{|c|c|c|c|c|c|c|c|c|}
\hline & \multicolumn{5}{|c|}{ Ground Reaction Force } & \multicolumn{3}{|c|}{ Flexion } \\
\hline & \multirow[b]{2}{*}{$\begin{array}{c}\text { No. } \\
\text { Stances }\end{array}$} & \multicolumn{2}{|c|}{ 1st Peak } & \multicolumn{2}{|c|}{ 2nd Peak } & \multirow[b]{2}{*}{$\begin{array}{c}\text { No. } \\
\text { Stances }\end{array}$} & \multirow{2}{*}{$\begin{array}{c}\text { Hip } \\
\text { Onset } \\
\text { (\% stance phase), } \\
\text { Mean } \pm \text { SD }\end{array}$} & \multirow{2}{*}{$\begin{array}{c}\text { Knee } \\
\text { Onset } \\
\% \text { stance phase), } \\
\text { Mean } \pm \text { SD }\end{array}$} \\
\hline & & $\begin{array}{l}\text { \% Stance } \\
\text { Phase }\end{array}$ & $\begin{array}{c}\% \text { BW, } \\
\text { Mean } \pm \text { SD }\end{array}$ & $\begin{array}{l}\text { \% Stance } \\
\text { Phase }\end{array}$ & $\begin{array}{c}\% \text { BW, } \\
\text { Mean } \pm \text { SD }\end{array}$ & & & \\
\hline$\overline{\mathrm{A} 1}$ & 19 & 15.3 & $99.9 \pm 0.01$ & 70.8 & $97.4 \pm 0.01$ & 18 & $97.4 \pm 0.9$ & $58.4 \pm 0.5$ \\
\hline A2 & 23 & 22.1 & $97.0 \pm 0.03$ & 63.2 & $93.6 \pm 0.02$ & 15 & $93.6 \pm 1.3$ & $65.9 \pm 0.9$ \\
\hline A3 & 21 & 26.9 & $99.9 \pm 0.03$ & 71.9 & $94.2 \pm 0.01$ & 7 & $94.2 \pm 1.1$ & $88.9 \pm 1.2$ \\
\hline A4 & 27 & 24.8 & $103.0 \pm 0.03$ & 70.7 & $89.9 \pm 0.03$ & 23 & $89.9 \pm 1.3$ & $65.4 \pm 0.3$ \\
\hline A5 & 18 & 27.0 & $99.3 \pm 0.02$ & 69.2 & $92.3 \pm 0.02$ & 16 & $92.3 \pm 1.7$ & $63.5 \pm 1.1$ \\
\hline Median & 21 & 24.8 & 99.9 & 70.7 & 93.6 & 16 & 93.6 & 65.4 \\
\hline Range & $18-27$ & $15.3-27.0$ & 97-103 & $63.2-71.9$ & 89.9-97.4 & $7-23$ & 89.9-97.4 & $58.4-88.9$ \\
\hline
\end{tabular}

of the stance phase. The secondary peak of sEMG activity also displayed a temporal difference, with GMAX, $\mathrm{RF}$, and BF having a peak at 75 percent of the stance phase, whereas GMED peaked at 65 percent and AM at 85 percent of the stance phase. The muscle activity for group B was broadly similar to group A, although for all muscles, the minimal activity occurred later in the stance cycle for group B (Figure 5). Additionally in group B, GMED reached its second peak 23 percent later in the stance phase, AM exhibited a peak early in stance, and BF did not exhibit a second peak of activity before toeoff but increased steadily from midcycle until end stance.

Two of the five individuals with TFA had a CMC above 0.80 , suggesting low variability, for at least one of the hip muscles, with subject A3 having a CMC above 0.80 for all muscles (Table 6). Although the highest median CMC of 0.77 across subjects was for AM, subjects A2 and A4 had low values of only 0.34 and 0.16 . There was, therefore, no muscle that consistently produced a high CMC value across the individuals with TFA.
For group B, GMED had the highest median CMC at 0.82 , with 5 of the 10 subjects attaining CMC values above 0.80 . The control subjects had a higher mean CMC for all muscles except BF. However, the individual across both groups with the highest repeatability was group $\mathrm{A}$ subject A3.

\section{DISCUSSION}

This study set out primarily to investigate function of muscles in the residual limb of individuals with TFA fitted with OFs. No published information is available regarding the effect of multiple surgeries on the function of the traumatized muscle. What this study shows is that the muscles investigated exhibited cyclical activity patterns similar to those recorded in nondisabled subjects. This contrasts with what has been reported in subjects with high-level TFAs fitted with conventional socket 


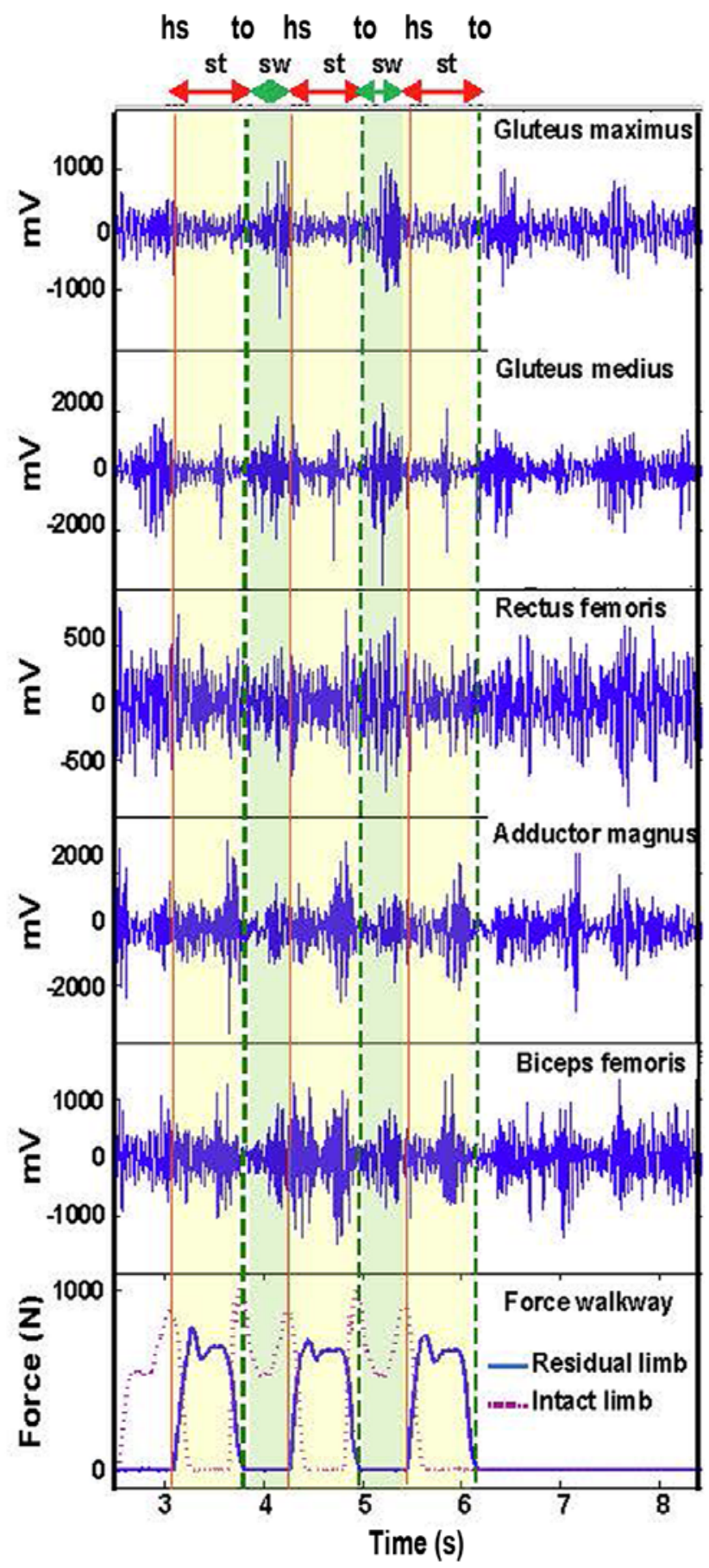

Figure 4.

Bandpass-filtered unnormalized output surface electromyography and force plate trace for residual limb of subject A1 for single trial. hs = heel strike, $\mathrm{st}=$ stance phase (shaded yellow), sw = swing phase (shaded green), to = toe-off.

prostheses in whom a constant level of muscle activity was present. Clinically, the results indicate that the OF has the beneficial effect of decreasing motor activity in the residual limb, leading to a potential reduction of energy expenditure that could enable individuals with TFA to walk faster. The main differences in patterns between the two groups were the absence of an initial burst of activity in AM and the increased activity of both AM and GMED during late stance, which may explain the increased hip hiking that is observed in individuals with OFs. This may be due to lack of firm fixation of AM-further investigation is needed. The variability of all muscle activity was high, and variability of the hip abductor, GMED, was significantly higher than in the nondisabled group. Clinically, the high variability between stances results in single-muscle sEMG being unsuitable as a myoprocessor. The only subject fitted with a C-Leg (Ottobock; Minneapolis, Minnesota) did, however, display high reproducibility for all muscles. This presents the exciting possibility that a microprocessor-controlled prosthesis modulates neurolocomotor activity, producing consistent patterns of sEMG. The following sections briefly present the findings and compare them with previous studies. Kinematic data were not collected from the nondisabled group.

\section{Temporospatial Parameters}

Overall, the significantly longer gait-cycle duration and stance phase percentage for group A compared with group B were in keeping with the literature. The walking speed was not, however, significantly different between the two groups. The walking speed recorded in group A was greater than that reported in previous studies in subjects with conventional socket prostheses [39-43]. The greater comfortable walking speed may be the result of the direct transmission of force between the femur and prosthetic limb in individuals with OFs, providing more confidence to load the prosthetic limb. This confirms that TFAs with fixation have the ability to translate the prosthetic benefits associated with fixation into increased functional outcomes [44]. Comparison of the temporospatial parameters in group A with a previous study on 12 individuals with OF by Frossard et al. (2010) shows the cadence was higher, gait cycle shorter, and stance support phase longer [45]. This may reflect that the median age was lower in our study than in Frossard et al. (37 vs 47.5 yr, respectively).

\section{Ground Reaction Force}

The GRF can be considered the end parameter, providing information about forces transmitted between the 

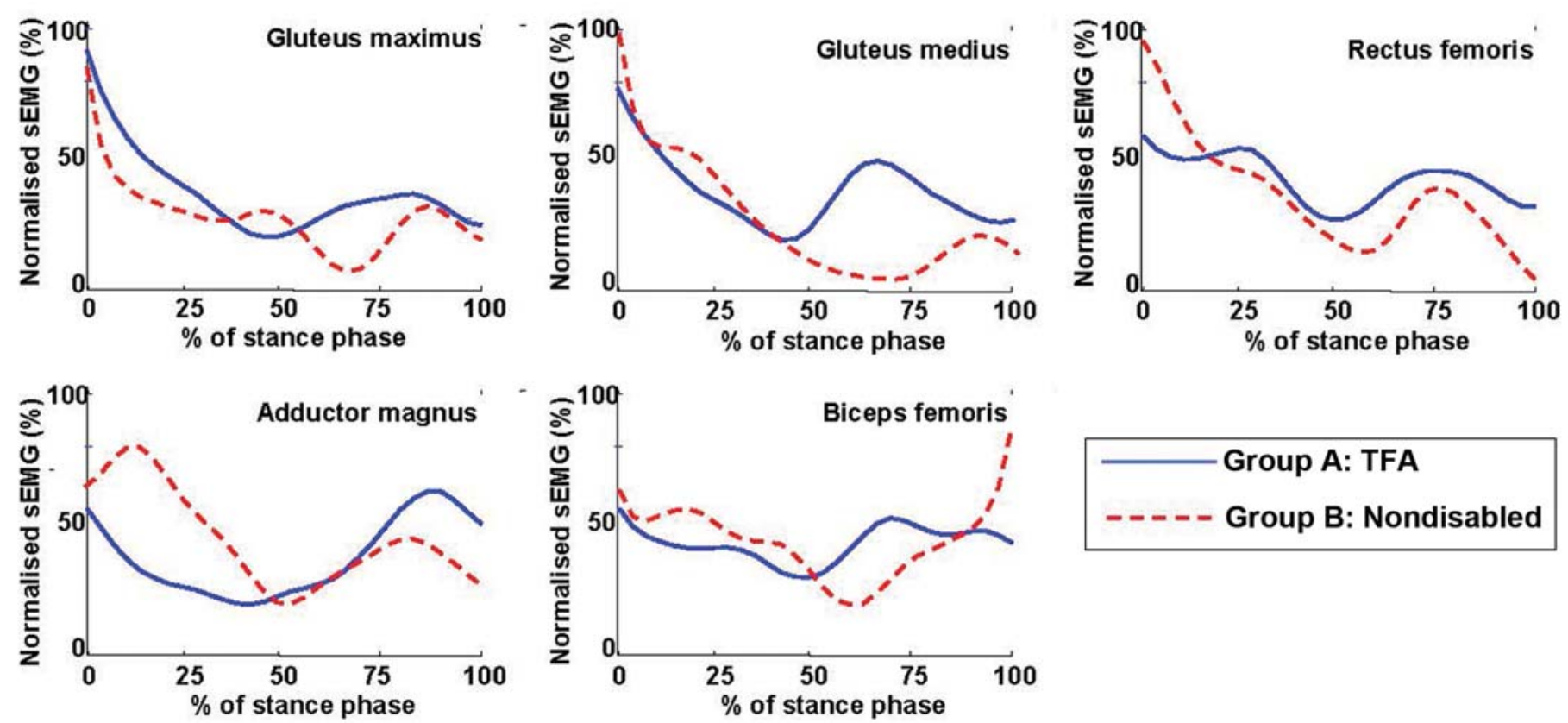

Figure 5.

Mean moving average values for residual limb (group with transfemoral amputation [TFA] $n=5$ ) and right lower limb (nondisabled group, $n=10$ ) for five hip muscles for stance phase. Group mean determined from average of each group subject's mean value. Length of smoothing window $=100 \mathrm{~ms}$.

subject and the external environment essential to advance the center of mass forward, the ultimate goal of locomotion. The double-peaked profiles of the vertical component of the GRF for group A were similar to those reported in subjects with intact limbs, although maximum amplitudes were lower. Small differences in GRF patterns were present between the 5 individuals with TFA, similar to the variations reported in axial loading of the prosthesis [29]. The interstance reproducibility for the vertical component of the GRFs for the individuals with TFAs was high, which has also been reported for nondisabled subjects [46-47].

\section{Hip Joint Kinematics}

The median maximum extension of $16.2^{\circ}$ was greater than the $9.9^{\circ}$ measured previously in individuals with OFs and in subjects with conventional socket prostheses, where the socket constrains movement [48]. In contrast to extension, the median maximum abduction $\left(13.2^{\circ}\right)$ recorded during stance was similar to the value of $10^{\circ}$ measured in subjects with conventional prostheses [49]. The variable patterns between subjects in internal/external rotation supports findings by Lee et al. (2008), who reported considerable variability between individuals with
OFs in internal and external moments around the longitudinal axis of the femur in the residual limb [29]. A number of factors account for the intersubject differences, including the type of prosthesis fitted, varying lengths of residual limbs, difference in muscle and nerve lesioning, natural variations in morphology, and different modes of neuromuscular control mechanisms. Interstance repeatability for the hip kinematic parameters was high, however, with a CMC above 0.80 for most of the individuals with TFA. The high repeatability of these parameters is remarkable, given the shortness of the residual limb; lack of proprioceptive feedback from the knee, ankle, and foot joints; and an absence of input from the cutaneous foot receptors. One proposed benefit of the OF over the socket prosthesis is increased proprioception mediated through osseous receptors [50] providing more feedback to neurolocomotor pathways and potentially producing a more stable gait pattern. No published information on intrasubject kinematic variability in individuals with TFA with socket prostheses is available with which to compare the $\mathrm{OF}$ data. The CMCs of the hip kinematic variables reported for nondisabled subjects in the sagittal, coronal, and transverse are $0.996 \pm 0.003,0.96 \pm 0.03$, and $0.89 \pm 0.06$, respectively [37]. These higher CMC values support the 
Table 6.

Coefficient of multiple correlations for five hip joint muscles for group A (subjects A1-A5 with transfemoral amputation) and group B (subjects B1-B10 with intact limbs).

\begin{tabular}{|c|c|c|c|c|c|c|c|}
\hline Subject & $\begin{array}{c}\text { Gluteus } \\
\text { Maximus }\end{array}$ & $\begin{array}{l}\text { Gluteus } \\
\text { Medius }\end{array}$ & $\begin{array}{c}\text { Rectus } \\
\text { Femoris }\end{array}$ & $\begin{array}{c}\text { Adductor } \\
\text { Magnus }\end{array}$ & Biceps Femoris & Median & Range \\
\hline \multicolumn{8}{|l|}{ Group A } \\
\hline A1 & 0.40 & 0.33 & 0.21 & 0.77 & 0.47 & 0.40 & $0.21-0.77$ \\
\hline A3 & 0.92 & 0.83 & 0.89 & 0.85 & 0.90 & 0.89 & $0.83-0.92$ \\
\hline A4 & 0.11 & 0.43 & 0.23 & 0.16 & 0.37 & 0.23 & $0.11-0.43$ \\
\hline Range & $0.11-0.92$ & $0.29-0.83$ & $0.21-0.89$ & $0.16-0.85$ & $0.37-0.90$ & $0.26-0.89$ & - \\
\hline \multicolumn{8}{|l|}{ Group B } \\
\hline B1 & 0.61 & 0.94 & 0.38 & 0.78 & 0.42 & 0.61 & $0.38-0.94$ \\
\hline B2 & 0.72 & 0.87 & 0.73 & 0.67 & 0.82 & 0.73 & $0.67-0.87$ \\
\hline B3 & 0.53 & 0.72 & 0.58 & 0.78 & 0.27 & 0.58 & $0.27-0.78$ \\
\hline B7 & 0.51 & 0.77 & 0.85 & 0.82 & 0.47 & 0.77 & $0.47-0.85$ \\
\hline B8 & 0.4 & 0.55 & 0.79 & 0.90 & 0.58 & 0.58 & $0.4-0.90$ \\
\hline B9 & 0.72 & 0.69 & 0.42 & 0.88 & 0.43 & 0.69 & $0.42-0.88$ \\
\hline B10 & 0.66 & 0.92 & 0.54 & 0.75 & 0.59 & 0.66 & $0.54-0.92$ \\
\hline Median & 0.57 & $0.82^{*}$ & 0.61 & 0.78 & 0.52 & 0.65 & - \\
\hline Range & $0.40-0.72$ & $0.55-0.94$ & $0.38-0.85$ & $0.47-0.93$ & $0.27-0.82$ & $0.58-0.85$ & - \\
\hline
\end{tabular}

principle that subjects with an intact musculoskeletal and neurological system have a higher level of neuromotor control and, therefore, repeatability.

\section{Surface Electromyography}

All five hip muscles in group A displayed cyclical sEMG activity during locomotion, with a dip in activity occurring during midstance when the lower limb was vertical. The minimum occurred earlier for individuals with TFA, which may be associated with an earlier onset of knee flexion compared with that reported in nondisabled subjects [51]. Specific differences in individual muscles between the two groups included an earlier, more pronounced peak of activity in GMED in group A corresponding to their second GRF peak, when unloading commenced (Table 5). This may contribute to hip hiking late in the swing cycle of the intact limb commonly present in individuals with TFA, particularly in subjects fitted with OFs [12,52]. AM, a major stabilizer of the hip, also displayed a greater increase in activity at end of support in the group with TFA than in the control group [23,53].
However, there was no initial burst during early stance as exhibited by the control group. This absence of activity may be related to the lack of surgical fixation of AM. A previous study reported a significant increase in the sEMG median frequency of AM, suggesting possible changes in motor unit recruitment with clinical implications for force of muscle contraction and fatigue [28]. In the individuals with TFA, the BF amplitude plateaued at about 75 percent of the stance phase, whereas for the nondisabled subjects, the mean value steadily increased with a sharp rise during end of support as the knee flexed. Both groups exhibited large intersubject variations for BF, which have also been reported by Patla (1985) in nondisabled subjects [54]. The mean sEMG patterns for GMAX and RF were similar between the groups. This result was unexpected for RF because it is converted to a uniarticular muscle and, therefore, subjected to altered afferent input. This observation is suggestive of a central pattern generator emitting a basic set of motor commands that are only partially modified following major trauma to the lower limb. How the sEMG activity recorded for 
the five muscles translates to functional activity cannot be directly stated because forces were not quantified in this study. However, the profiles of GMAX, RF, and AM resemble the mean hip joint moments in the frontal and sagittal planes estimated in a previous study [31].

How do the patterns of sEMG activity during stance from individuals with OFs compare with sEMG from subjects with conventional socket prostheses? The few studies undertaken on SEMG in residual muscles of individuals with TFA and conventional socket prostheses have mostly involved small numbers of participants, with the largest investigation by Jaegers et al. (1996), who reported that GMAX, GMED, RF, and BF displayed constant activity in individuals with short residual limbs following TFA [27]. These findings suggest that in this subgroup, where good socket attachment is an issue, the muscles cocontract to improve stability. However, in subjects with OFs, there is no socket, and therefore, the muscles do not have to satisfy the dual-motor task demand of providing socket stability and locomotion, but rather the single task of motor activation necessary to generate locomotion.

The sEMG displayed low repeatability because of factors including noise and interference, placement of electrodes, and changing neural input [55]. The changing neural input is related to the indeterminate number of ways in which the muscles can achieve the desired movement [56]. The level of sEMG variability differed between individuals with OFs, with subject A3 displaying high repeatability. This subject had the highest mass of $98.2 \mathrm{~kg}$, was the youngest participant with TFA, and the only one fitted with a C-Leg prosthesis. The latter suggests that the C-Leg may provide a modulating influence on regulation of neurolocomotor signals. Subject A3 also exhibited a difference in knee kinematics, with no knee flexion occurring during the loading phase and knee flexion commencing late in the stance phase (Table 5). Another gait difference was that the time taken to reach peak GRF for subject A3 was long (26.9\% of stance phase). No published reports of variability of sEMG during gait in individuals with TFA with conventional socket prostheses are available for comparison.

The CMC for the abductor GMED was significantly lower in group A than group B, which may reflect the diminished function of its antagonist, AM. This greater variability for GMED suggests greater variability in control of mediolateral movements. A study of individuals with TFA with socket prostheses reported increased variability in mediolateral trunk acceleration [57].

\section{Limitations}

The study did not include a group with TFA fitted with conventional socket prostheses. Although the data were compared with published data, the epidemiological features of the two cohorts are likely to be different. Additionally, there may be differences in methodology, for example, in determining joint angle. No kinematic recordings were made of the control group, thereby precluding comparison of kinematic data between the two groups. The study did not investigate the current risks of OFs, particularly infection and the lengthy rehabilitation process. Any potential advantage must be weighed against the known risk factors.

\section{CONCLUSIONS}

The first hypothesis, that there would be an absence of cyclical pattern of muscle activity in individuals with OFs, was not supported. All five of the hip muscles recorded displayed cyclical patterns of sEMG activity suggestive of functional ability to contract and exert a moment about the hip joint. Patterns of sEMG recordings were broadly similar between individuals with TFA and nondisabled subjects, the main difference being phase of maxima and minima. The second hypothesis, that variability of muscle activity would be greater in individuals with OFs than in subjects with intact limbs, was supported. The implications for the viability of a myoprocessor in individuals with TFA are that normalized amplitude is too variable to permit single muscles to be used. Instead, features such as temporal occurrence of local minima or maxima that relate to loading and hip kinematics should be explored. However, one individual with OF, and the only subject fitted with a C-Leg, had high repeatability of sEMG recordings for all muscles. This suggests that microprocessor-controlled prostheses may modulate neurolocomotor signals, resulting in a highly repeatable signal that could function as a myoprocessor.

\section{ACKNOWLEDGMENTS}

\section{Author Contributions:}

Study concept and design: A. Pantall, D. Ewins. Acquisition of data: A. Pantall, D. Ewins. 
Analysis and interpretation of data: A. Pantall, D. Ewins.

Drafting of manuscript: A. Pantall.

Critical revision of manuscript for important intellectual content:

A. Pantall, D. Ewins.

Statistical analysis: A. Pantall.

Additional Contributions: The authors thank Sally Durham for her assistance with data acquisition. Annette Pantall is now with the College of Osteopathic Medicine, Michigan State University.

Financial Disclosures: The authors have declared that no competing interests exist.

Funding/Support: This material was based on work supported by the U.K. Department of Health subvention fund.

Institutional Review: Ethical approval for the study was granted by the Wandsworth Local Research Ethics Committee at St. George's

Hospital, London, United Kingdom. Informed consent was obtained from all subjects before participation.

Participant Follow-Up: The authors plan to inform participants of the publication of this study.

\section{REFERENCES}

1. Martin J, Pollock A, Hettinger J. Microprocessor lower limb prosthetics: review of current state of the art. J Prosthet Orthot. 2010;22(3):183-93.

2. Pezzin LE, Dillingham TR, Mackenzie EJ, Ephraim P, Rossbach P. Use and satisfaction with prosthetic limb devices and related services. Arch Phys Med Rehabil. 2004;85(5):723-29. [PMID:15129395]

http://dx.doi.org/10.1016/j.apmr.2003.06.002

3. Murphy EF. History and philosophy of attachment of prostheses to the musculo-skeletal system and of passage through the skin with inert materials. J Biomed Mater Res. 1973;7(3):275-95. [PMID:4577874]

http://dx.doi.org/10.1002/jbm.820070319

4. Brånemark R, Brånemark PI, Rydevik B, Myers RR. Osseointegration in skeletal reconstruction and rehabilitation: a review. J Rehabil Res Dev. 2001;38(2):175-81. [PMID:11392650]

5. Kang NV, Pendegrass C, Marks L, Blunn G. Osseocutaneous integration of an intraosseous transcutaneous amputation prosthesis implant used for reconstruction of a transhumeral amputee: case report. J Hand Surg. 2010; 35(7):1130-34.

6. Blunn GW, Pendegrass C. Development of an intraosseous transcutaneous amputation prostheses (ITAP). 2011 MyoElectric Controls/Powered Prosthetics Symposium; 2011; Fredericton, New Brunswick, Canada.

7. Aschoff HH, Clausen A, Hoffmeister T. [The endo-exo femur prosthesis - a new concept of bone-guided, prosthetic rehabilitation following above-knee amputation]. Z Orthop Unfall. 2009;147(5):610-15. German.

[PMID:19938359]

http://dx.doi.org/10.1055/s-0029-1185893
8. Aschoff HH, Kennon RE, Keggi JM, Rubin LE. Transcutaneous, distal femoral, intramedullary attachment for abovethe-knee prostheses: an endo-exo device. J Bone Joint Surg Am. 2010;92(Suppl 2):180-86. [PMID:21123601] http://dx.doi.org/10.2106/JBJS.J.00806

9. Hagberg K, Brånemark R. One hundred patients treated with osseointegrated transfemoral amputation prosthesesrehabilitation perspective. J Rehabil Res Dev. 2009;46(3): 331-44. [PMID:19675986] http://dx.doi.org/10.1682/JRRD.2008.06.0080

10. Hagberg K, Brånemark R, Gunterberg B, Rydevik B. Osseointegrated trans-femoral amputation prostheses: prospective results of general and condition-specific quality of life in 18 patients at 2-year follow-up. Prosthet Orthot Int. 2008;32(1):29-41. [PMID:18330803] http://dx.doi.org/10.1080/03093640701553922

11. Hagberg K, Häggström E, Uden M, Brånemark R. Socket versus bone-anchored trans-femoral prostheses: hip range of motion and sitting comfort. Prosthet Orthot Int. 2005; 29(2):153-63. [PMID:16281724]

http://dx.doi.org/10.1080/03093640500238014

12. Sullivan J, Uden M, Robinson KP, Sooriakumaran S. Rehabilitation of the trans-femoral amputee with an osseointegrated prosthesis: the United Kingdom experience. Prosthet Orthot Int. 2003;27(2):114-20. [PMID:14571941] http://dx.doi.org/10.1080/03093640308726667

13. Lundberg M, Hagberg K, Bullington J. My prosthesis as a part of me: a qualitative analysis of living with an osseointegrated prosthetic limb. Prosthet Orthot Int. 2011;35(2): 207-14. [PMID:21697203] http://dx.doi.org/10.1177/0309364611409795

14. Wetz HH, Jacob HA. [Synergism between joint mechanics and stump muscles in upper leg amputees. Arguments for a myotenodesis of the greater adductor muscle]. Z Orthop Ihre Grenzgeb. 1994;132(3):244-49. German. [PMID:8048265] http://dx.doi.org/10.1055/s-2008-1039970

15. Weir RF, Heckathorne CW, Childress DS. Cineplasty as a control input for externally powered prosthetic components. J Rehabil Res Dev. 2001;38(4):357-63. [PMID:11563487]

16. Pitkin M, Cassidy C, Muppavarapu R, Edell D. Recording of electric signal passing through a pylon in direct skeletal attachment of leg prostheses with neuromuscular control. IEEE Trans Biomed Eng. 2012;59(5):1349-53. [PMID:22345523]

http://dx.doi.org/10.1109/TBME.2012.2187784

17. Cavallaro EE, Rosen J, Perry JC, Burns S. Real-time myoprocessors for a neural controlled powered exoskeleton arm. IEEE Trans Biomed Eng. 2006;53(11):2387-96.

[PMID:17073345]

http://dx.doi.org/10.1109/TBME.2006.880883 
18. Hudgins B, Parker P, Scott RN. A new strategy for multifunction myoelectric control. IEEE Trans Biomed Eng. 1993;40(1):82-94. [PMID:8468080] http://dx.doi.org/10.1109/10.204774

19. Kuruganti U, Hudgins B, Scott RN. Two-channel enhancement of a multifunction control system. IEEE Trans Biomed Eng. 1995;42(1):109-11. [PMID:7851924] http://dx.doi.org/10.1109/10.362912

20. Kwon J, Lee D, Lee S, Kim N, Hong S, editors. EMG signals recognition for continuous prosthetic arm control purpose. Proceedings of IEEE Asia Pacific Conference on Circuits and Systems; 1996 Nov 18-21; Seoul, Korea.

21. Bonato P, Roy SH, Knaflitz M, De Luca CJ. Time-frequency parameters of the surface myoelectric signal for assessing muscle fatigue during cyclic dynamic contractions. IEEE Trans Biomed Eng. 2001;48(7):745-53. [PMID:11442286] http://dx.doi.org/10.1109/10.930899

22. Robinson KP, Brånemark R, Ward D. Future developments: osseointegration in transfemoral amputees. In: Smith DG, Michael JW, Bowker JH, editors. Atlas of amputations and limb deficiencies: Surgical, prosthetic and rehabilitation principles. 3d ed. Rosemont (IL): American Academy of Orthopaedic Surgeons; 2004. p. 673-81.

23. Gottschalk F. Transfemoral amputation. Biomechanics and surgery. Clin Orthop Relat Res. 1999;361(361):15-22. [PMID:10212591] http://dx.doi.org/10.1097/00003086-199904000-00003

24. Jaegers SM, Arendzen JH, de Jongh HJ. Changes in hip muscles after above-knee amputation. Clin Orthop Relat Res. 1995;319(319):276-84.[PMID:7554640]

25. Schmalz T, Blumentritt S, Jarasch R. Energy expenditure and biomechanical characteristics of lower limb amputee gait: the influence of prosthetic alignment and different prosthetic components. Gait Posture. 2002;16(3):255-63. [PMID:12443950] http://dx.doi.org/10.1016/S0966-6362(02)00008-5

26. Baum BS, Schnall BL, Tis JE, Lipton JS. Correlation of residual limb length and gait parameters in amputees. Injury. 2008;39(7):728-33. [PMID:18541239] http://dx.doi.org/10.1016/j.injury.2007.11.021

27. Jaegers SM, Arendzen JH, de Jongh HJ. An electromyographic study of the hip muscles of transfemoral amputees in walking. Clin Orthop Relat Res. 1996;328(328):119-28. [PMID:8653944]

http://dx.doi.org/10.1097/00003086-199607000-00020

28. Pantall A, Durham S, Ewins D. Surface electromyographic activity of five residual limb muscles recorded during isometric contraction in transfemoral amputees with osseointegrated prostheses. Clin Biomech (Bristol, Avon). 2011; 26(7):760-65. [PMID:21474221] http://dx.doi.org/10.1016/j.clinbiomech.2011.03.008
29. Lee WC, Frossard LA, Hagberg K, Haggstrom E, Gow DL, Gray S, Brånemark R. Magnitude and variability of loading on the osseointegrated implant of transfemoral amputees during walking. Med Eng Phys. 2008;30(7):825-33.

[PMID:17977050]

http://dx.doi.org/10.1016/j.medengphy.2007.09.003

30. Burger H, Marincek C. The life style of young persons after lower limb amputation caused by injury. Prosthet Orthot Int. 1997;21(1):35-39. [PMID:9141124]

31. Frossard L, Cheze L, Dumas R. Dynamic input to determine hip joint moments, power and work on the prosthetic limb of transfemoral amputees: ground reaction vs knee reaction. Prosthet Orthot Int. 2011;35(2):140-49.

[PMID:21697197]

http://dx.doi.org/10.1177/0309364611409002

32. Huang H, Kuiken TA, Lipschutz RD. A strategy for identifying locomotion modes using surface electromyography.

IEEE Trans Biomed Eng. 2009;56(1):65-73.

[PMID:19224720]

http://dx.doi.org/10.1109/TBME.2008.2003293

33. Freriks B, Hermens HJ. European recommendations for surface electromyography. Biomedical and health research project: SENIAM Project 2000. Enschede (the Netherlands): Roessingh Research and Development; 2000.

34. Hynd D, Hughes SC, Ewins DJ. The development of a long, dual-platform triaxial walkway for the measurement of forces and temporal-spatial data in the clinical assessment of gait. Proc Inst Mech Eng H. 2000;214(2):193-201. [PMID:10825776] http://dx.doi.org/10.1243/0954411001535354

35. Hof AL. Scaling gait data to body size. Gait Posture. 1996;4:222-23. http://dx.doi.org/10.1016/0966-6362(95)01057-2

36. Yang JF, Winter DA. The effect of EMG normalisation methods in intersubject variability. Proceedings of the 2nd Biannual Conference of the Canadian Society for Biomechanics; Kingston, Ontario; 1982 Aug 31- Sep 3; Ottawa, Ontario (Canada): Canadian Society of Biomechanics; 1982. p. 88-89.

37. Kadaba MP, Ramakrishnan HK, Wootten ME, Gainey J, Gorton G, Cochran GV. Repeatability of kinematic, kinetic, and electromyographic data in normal adult gait. J Orthop Res. 1989;7(6):849-60. [PMID:2795325] http://dx.doi.org/10.1002/jor.1100070611

38. Collins TD, Ghoussayni SN, Ewins DJ, Kent JA. A six degrees-of-freedom marker set for gait analysis: repeatability and comparison with a modified Helen Hayes set. Gait Posture. 2009;30(2):173-80. [PMID:19473844] http://dx.doi.org/10.1016/j.gaitpost.2009.04.004

39. Growney E, Meglan D, Johnson M, Cahalan T, An K-N. Repeated measures of adult normal walking using a video 
tracking system. Gait Posture. 1997;6:147-62. http://dx.doi.org/10.1016/S0966-6362(97)01114-4

40. Jaegers SM, Arendzen JH, de Jongh HJ. Prosthetic gait of unilateral transfemoral amputees: a kinematic study. Arch Phys Med Rehabil. 1995;76(8):736-43. [PMID:7632129] http://dx.doi.org/10.1016/S0003-9993(95)80528-1

41. Bae TS, Choi K, Hong D, Mun M. Dynamic analysis of above-knee amputee gait. Clin Biomech (Bristol, Avon). 2007;22(5):557-66. [PMID:17321021]

http://dx.doi.org/10.1016/j.clinbiomech.2006.12.009

42. Hafner BJ, Willingham LL, Buell NC, Allyn KJ, Smith DG. Evaluation of function, performance, and preference as transfemoral amputees transition from mechanical to microprocessor control of the prosthetic knee. Arch Phys Med Rehabil. 2007;88(2):207-17. [PMID:17270519] http://dx.doi.org/10.1016/j.apmr.2006.10.030

43. Highsmith MJ, Schulz BW, Hart-Hughes S, Latlief GA, Phillips SL. Differences in the spatiotemporal parameters of transtibial and individual with transfemoral amputation gait. J Prosthet Orthot. 2010;22(1):26-30. http://dx.doi.org/10.1097/JPO.0b013e3181cc0e34

44. Boonstra AM, Schrama J, Fidler V, Eisma WH. The gait of unilateral transfemoral amputees. Scand J Rehabil Med. 1994;26(4):217-23. [PMID:7878397]

45. Frossard L, Hagberg K, Häggstrom E, Gow DL, Brånemark R, Pearcy M. Functional outcome of transfemoral amputees fitted with an osseointegrated fixation: temporal gait characteristics. J Prosthet Orthot. 2010;22(1):11-20. http://dx.doi.org/10.1097/JPO.0b013e3181ccc53d

46. Giakas G, Baltzopoulos V. A comparison of automatic filtering techniques applied to biomechanical walking data. J Biomech. 1997;30(8):847-50. [PMID:9239571] http://dx.doi.org/10.1016/S0021-9290(97)00042-0

47. Masani K, Kouzaki M, Fukunaga T. Variability of ground reaction forces during treadmill walking. J Appl Physiol. 2002;92(5):1885-90. [PMID:11960938]

48. Tranberg R, Zügner R, Kärrholm J. Improvements in hipand pelvic motion for patients with osseointegrated transfemoral prostheses. Gait Posture. 2011;33(2):165-68.

[PMID:21130654] http://dx.doi.org/10.1016/j.gaitpost.2010.11.004

49. Perry J, Burnfield JM, Newsam CJ, Conley P. Energy expenditure and gait characteristics of a bilateral amputee walking with C-Leg prostheses compared with stubby and conventional articulating prostheses. Arch Phys Med Rehabil. 2004;85(10):1711-17. [PMID:15468036] http://dx.doi.org/10.1016/j.apmr.2004.02.028
50. Jacobs R, Brånemark R, Olmarker K, Rydevik B, Van Steenberghe D, Brånemark P-I. Evaluation of the psychophysical detection threshold level for vibrotactile and pressure stimulation of prosthetic limbs using bone anchorage or soft tissue support. Prosthet Orthot Int. 2000;24(2):133-42. [PMID:11061200]

http://dx.doi.org/10.1080/03093640008726536

51. Perry J. Gait analysis. Normal and pathological function. Thorofare (NJ): SLACK Inc; 1992.

52. Michaud SB, Gard SA, Childress DS. A preliminary investigation of pelvic obliquity patterns during gait in persons with transtibial and transfemoral amputation. J Rehabil Res Dev. 2000;37(1):1-10. [PMID:10847567]

53. Németh G, Ohlsén H. In vivo moment arm lengths for hip extensor muscles at different angles of hip flexion. J Biomech. 1985;18(2):129-40. [PMID:3988782] http://dx.doi.org/10.1016/0021-9290(85)90005-3

54. Patla AE. Some characteristics of EMG patterns during locomotion: implications for the locomotor control process. J Mot Behav. 1985;17(4):443-61. [PMID:15140675]

55. Rainoldi A, Galardi G, Maderna L, Comi G, Lo Conte L, Merletti R. Repeatability of surface EMG variables during voluntary isometric contractions of the biceps brachii muscle. J Electromyogr Kinesiol. 1999;9(2):105-19.

56. Winter DA. Biomechanics and motor control of human movement. 3d ed. Hoboken (NJ): John Wiley \& Sons; 2005.

57. Lamoth CJ, Ainsworth E, Polomski W, Houdijk H. Variability and stability analysis of walking of transfemoral amputees. Med Eng Phys. 2010;32(9):1009-14.

[PMID:20685147]

http://dx.doi.org/10.1016/j.medengphy.2010.07.001

Submitted for publication October 27, 2011. Accepted in revised form October 9, 2012.

This article and any supplementary material should be cited as follows:

Pantall A, Ewins D. Muscle activity during stance phase of walking: Comparison of males with transfemoral amputation with osseointegrated fixations to nondisabled male volunteers. J Rehabil Res Dev. 2013;50(4):499-514. http://dx.doi.org/10.1682/JRRD.2011.10.0204

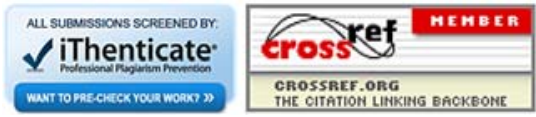

